\title{
Bromfenac ophthalmic solution for the treatment of postoperative ocular pain and inflammation: safety, efficacy, and patient adherence
}

This article was published in the following Dove Press journal:

Patient Preference and Adherence

25 June 2014

Number of times this article has been viewed

\author{
Rajesh K Rajpal \\ Bryan Ross \\ Sachin D Rajpal \\ Khoa Hoang \\ See Clearly Vision Group, McLean, \\ VA, USA
}

\begin{abstract}
Ophthalmic nonsteroidal anti-inflammatory drugs (NSAIDs) are commonly used by clinicians to manage ocular inflammation and pain following cataract surgery. Over the past decade, the US Food and Drug Administration has approved multiple topical NSAIDs for these purposes, including several reformulated products. One of these medications, bromfenac ophthalmic solution, has a long and extensive history, with proven efficacy and safety in patients following cataract surgery. The evolution of bromfenac ophthalmic solution over the years has involved either lowering the concentration of the active ingredient or extending the dosing interval to improve patient adherence/compliance. This review will focus on the history and progression of bromfenac ophthalmic solution and report the available patient preference and adherence data regarding this ocular NSAID throughout its evolution.
\end{abstract}

Keywords: cataract surgery, nonsteroidal anti-inflammatory drugs, COX inhibitors

\section{Introduction}

Cataracts are the leading cause of visual impairment and preventable blindness worldwide, ${ }^{1,2}$ with bilateral age-related cataracts causing an estimated $43 \%$ of all cases of blindness worldwide. ${ }^{3}$ In the US, blindness or low vision is estimated to affect 1 in 28 people older than 40 years of age. ${ }^{4}$ The aging US population is expected to have a marked increase in these figures. ${ }^{4}$ Phacoemulsification with intraocular lens implantation has become the primary surgery to remove cataracts. However, with the surgery comes the potential for postoperative pain and inflammation, which have long been deemed as acceptable risks given the numerous benefits of cataract surgery. ${ }^{5}$ The use of nonsteroidal anti-inflammatory drugs (NSAIDs) has been shown to reduce postoperative pain, reduce the risk of postoperative inflammation, and improve patient comfort. ${ }^{6-10}$ Recent ophthalmic medications have been developed to improve product-related comfort, with the overall potential to improve patient preference and adherence.

\section{NSAIDs and postoperative inflammation}

NSAIDs have a long history as effective analgesics; their use in ophthalmic disorders has been well established. With respect to their mechanism of action, in short, NSAIDs inhibit cyclooxygenase (COX) at the site of inflammation. ${ }^{11} \mathrm{COX}$ inhibitors act upon the arachidonic acid pathway to inhibit the production of prostaglandins, thereby reducing inflammation. ${ }^{11-16}$ Since NSAIDs act at later stages in the arachidonic acid pathway than corticosteroids, they can achieve similar anti-inflammatory effects without the adverse events (AEs) common with steroid use (eg, increased intraocular pressure
Correspondence: Rajesh Rajpal

See Clearly Vision Group,

8138 Watson St, McLean,

VA 22102, USA

Email rrajpal@seeclearly.com 
and, in phakic patients, cataract development). ${ }^{17-20}$ Historically, clinicians have viewed ophthalmic NSAIDs as an essential component of the available treatment options for the management of ocular postoperative pain and inflammation. In the US, in order to decrease both intraoperative and post-surgical inflammation, it is now becoming commonplace to extend ophthalmic NSAID dosing to preoperative use as well, with clinicians opting to dose patients beginning 1-2 days prior to ocular surgery, continuing on the day of surgery, and for 2 or more weeks post-surgery to reduce inflammation and minimize the risk of postoperative complications, ${ }^{21}$ in particular to prevent postoperative cystoid macular edema (CME). In the US, the use of NSAIDs for the prevention of CME remains off-label, although there is convincing evidence in the literature. ${ }^{22-26} \mathrm{In}$ the European Union, nepafenac was the first NSAID granted marketing authorization for the prevention of CME.

\section{Chemical history of bromfenac Potency}

The bromfenac molecule has been evaluated extensively in Japan and the US. ${ }^{27-34}$ Bromfenac sodium is designated chemically as sodium 2-amino-3-(4-bromobenzoyl) phenylacetate sesquihydrate, with an empirical formula of $\mathrm{C}_{15} \mathrm{H}_{11} \mathrm{BrNNaO}_{3} \cdot 1 \frac{1}{2} \mathrm{H}_{2} \mathrm{O} \cdot{ }^{35}$ The addition of the bromine atom to the structure increases the potency and penetration of the molecule into ocular tissue. ${ }^{36-39}$ In preclinical studies, bromfenac was substantially more potent than other analgesics (by a factor ranging from 1.8 to 44.2 times) in mice, rabbits, and dogs at suppressing both acute and chronic inflammation. ${ }^{37}$ Ruiz et al also showed the addition of bromine to the molecule increased the potency against the cyclooxygenase (COX)-2 enzyme by increasing lipophilicity almost ten-fold in log scale terms. ${ }^{40}$

The potency of an NSAID is commonly measured as the necessary concentration of the drug to inhibit COX enzyme activity by $50 \%\left(\mathrm{IC}_{50}\right)$. Compared with other ophthalmic NSAIDs, bromfenac was shown to be approximately three-to-four times more potent at inhibiting COX-2, with an $\mathrm{IC}_{50}$ of $0.0075 \mu \mathrm{m}$ compared with amfenac $(0.0204 \mu \mathrm{m})$, ketorolac $(0.0279 \mu \mathrm{m})$, and diclofenac $(0.0307 \mu \mathrm{m}) .{ }^{39}$

\section{Ocular penetration}

To be considered an effective topical ophthalmic NSAID, the medication needs to be able to penetrate the affected tissue and remain in the tissue at sufficient levels throughout the dosing interval to be clinically effective. As the potency and the ability to inhibit prostaglandin production vary among the NSAIDs, so does the ability of the available
NSAIDs to penetrate ocular tissues. The pharmacokinetic properties associated with any particular NSAID are highly correlated with the molecular structure of the compound. ${ }^{41}$ Bromfenac has a chemical structure similar to amfenac (the active form of prodrug nepafenac), with the distinction of a bromine atom at the 4-position of the benzoyl ring. ${ }^{41}$ By halogenating the molecule, effective in vitro and in vivo potency and absorption across the cornea and into the ocular tissue have been demonstrated. ${ }^{41}$

A 24-hour pharmacokinetic evaluation of a single $50 \mu \mathrm{L}$ ${ }^{14} \mathrm{C}$-bromfenac ophthalmic solution $0.09 \%$ administered into eyes of New Zealand White rabbits found that after 24 hours, the highest concentrations of bromfenac were in the cornea, the conjunctiva, and the sclera. ${ }^{41}$ Similar amounts were detected in the aqueous humor, the iris-ciliary body, the choroid, and, to a slightly lesser degree, the retina. Measurable amounts of bromfenac were detected in all samples at the 24-hour time point ( $\geq 0.001 \mu \mathrm{g}$ equivalent/g). In a similar 12-hour pharmacokinetic study (Data on file, Bausch + Lomb, Irvine, CA, USA), the eyes of New Zealand White rabbits were instilled with $50 \mu \mathrm{L}$ of either ${ }^{14} \mathrm{C}$-labeled bromfenac $0.07 \%$, pH 7.8 or ${ }^{14} \mathrm{C}$-labeled bromfenac $0.09 \%$, $\mathrm{pH}$ 8.3. The highest concentrations of bromfenac-equivalent levels were found in the sclera, followed by the iris-ciliary body, the aqueous humor, the choroid, the retina, and the lens. The total amount of bromfenac-equivalents in all ocular tissues was higher in the eyes that received bromfenac $0.07 \%$ at four of five time points compared with those that received bromfenac $0.09 \%$.

\section{Clinical history of bromfenac Bromfenac 0.09\% (0.1\%)}

Bromfenac ophthalmic solution $0.1 \%$ was approved as Bronuck (Senju Pharmaceutical Co., Ltd., Osaka, Japan) in Japan in 2000, and is presently approved in Japan for the treatment of postoperative inflammation and anterior inflammatory diseases such as blepharitis, conjunctivitis, and scleritis. ${ }^{42}$ Bromfenac ophthalmic solution $0.09 \%$, the same as the hydrate-salt bromfenac $0.1 \%$ formulation, was approved in the US in 2005 as Xibrom (ISTA Pharmaceuticals Inc., Irvine, CA, USA) for the treatment of postoperative inflammation in patients who have undergone cataract extraction. This initial approval was then expanded in 2006 to include the reduction of ocular pain after cataract extraction. ${ }^{43}$

Formulated at $\mathrm{pH} 8.3$, bromfenac $0.09 \%$ dosed twicedaily showed superior clinical efficacy over placebo in achieving zero-to-trace anterior chamber inflammation $(0-5 \text { cells and the absence of flare })^{32}$ (Table 1). In 2010, 
Table I Bromfenac studies evaluating zero-to-trace anterior chamber inflammation

\begin{tabular}{|c|c|c|c|}
\hline Study & Treatments & $\begin{array}{l}\text { Number of eyes } \\
\text { (patients) }\end{array}$ & $\begin{array}{l}\text { Zero-to-trace inflammation } \\
\text { ( } 0-5 \text { cells with } 0 \text { flare) }\end{array}$ \\
\hline Donnenfeld et al ${ }^{29}$ & $\begin{array}{l}\text { Bromfenac } 0.09 \% \text {, twice daily } \\
(n=356) \\
\text { Placebo }(n=|7|)\end{array}$ & $\begin{array}{l}\mathrm{N}=527 \text { ( } 527) \\
\text { Patients with postoperative } \\
\text { SOIS } \geq 3 \text { were treated for } 14 \text { days } \\
\text { starting the day after surgery }\end{array}$ & $\begin{array}{l}64 \% \text { (bromfenac) vs } 43.3 \% \\
\text { (placebo) at study day } 15 \\
(P<0.000 \text { I) }\end{array}$ \\
\hline Silverstein et a ${ }^{32}$ & $\begin{array}{l}\text { Bromfenac } 0.09 \% \text {, once daily } \\
(n=230) \\
\text { Placebo }(n=225)\end{array}$ & $\begin{array}{l}\mathrm{N}=455 \text { ( } 455) \\
\text { Dosing began I day before } \\
\text { surgery, on the day of surgery, } \\
\text { and for I } 4 \text { days following surgery }\end{array}$ & $\begin{array}{l}73.9 \% \text { (bromfenac) vs } 40.4 \% \\
\text { (placebo) by day I5 } \\
(P<0.000 \mathrm{I})\end{array}$ \\
\hline Gow et a ${ }^{45, *}$ & $\begin{array}{l}\text { Bromfenac } 0.07 \% \text {, once daily } \\
(n=222) \\
\text { Placebo }(n=2 \mid 8)\end{array}$ & $\begin{array}{l}\mathrm{N}=440 \text { ( } 440) \\
\text { Dosing began I day before } \\
\text { surgery, on the day of surgery, } \\
\text { and for I } 4 \text { days following surgery }\end{array}$ & $\begin{array}{l}71.2 \% \text { (bromfenac) vs } 39.4 \% \\
\text { (placebo) by day I5 } \\
(P<0.000 \text { I) }\end{array}$ \\
\hline
\end{tabular}

Note: *Poster presented at the 2013 Association for Research in Vision and Ophthalmology meeting.

Abbreviations: SOIS, summed ocular inflammation score; vs, versus.

a once-daily formulation of bromfenac $0.09 \%$ (Bromday; ISTA Pharmaceuticals Inc.) was developed; this was the first once-daily ophthalmic NSAID in the US approved for the treatment of postoperative ocular inflammation and reduction of ocular pain in patients who have undergone cataract extraction with posterior chamber intraocular lens implantation. ${ }^{35}$ A study evaluating bromfenac $0.09 \%$ dosed once daily, also with a $\mathrm{pH}$ of 8.3 , found that $73.9 \%$ of the bromfenac $0.09 \%$ once-daily group reached zero-to-trace anterior chamber inflammation by day 15 compared with only $40.4 \%$ in the placebo group; the once-daily formulation provided similar efficacy to that of the bromfenac $0.09 \%$ twice-daily formulation. ${ }^{32}$

\section{Bromfenac 0.07\%}

A lower concentration of bromfenac, $0.07 \%$, dosed once daily was then evaluated to determine efficacy in the treatment of postoperative pain and inflammation associated with cataract surgery. The lower concentration included a more physiologic $\mathrm{pH}$ (7.8) to improve penetration into ocular tissues; the reduced $\mathrm{pH}$ also may improve comfort upon instillation for some patients. Limiting acute ocular surface exposure to a medication also may have an added benefit of a reduced incidence of AEs. This may be especially important with the use of NSAIDs, as in the past NSAID use has resulted in corneal erosions or melts - albeit a low incidence. ${ }^{44}$

The advanced formulation of bromfenac $0.07 \%$ was also effective in reducing ocular inflammation following cataract surgery, with significantly higher proportions of subjects having zero-to-trace anterior chamber inflammation compared with the placebo group as early as day 3 and through day $15 .{ }^{45}$ At day $15,71.2 \%$ of subjects in the bromfenac $0.07 \%$ group achieved zero-to-trace anterior chamber inflammation compared with $39.4 \%$ of subjects in the placebo group. ${ }^{45}$ Based in part on results of the Phase III clinical trials, on April 5, 2013 the US Food and Drug Administration approved once-daily use of bromfenac $0.07 \%$ (Prolensa; Bausch and Lomb Inc., Irvine, CA, USA) for the treatment of postoperative inflammation and reduction of ocular pain in patients who have undergone cataract surgery. ${ }^{6}$

Throughout the history of ophthalmic bromfenac, each new iteration has reduced either the dosing regimen (from twice daily to once daily) or the concentration and $\mathrm{pH}$ levels (from $0.09 \%, \mathrm{pH} 8.3$ to $0.07 \%, \mathrm{pH} 7.8$ ). The only other NSAID approved for once-daily dosing is nepafenac, which has triple the drug concentration of its three-times-daily formulation.

\section{Safety profile}

The safety of the bromfenac molecule has remained consistent throughout the various formulations, and AEs have been minimal in most studies. Patient-reported comfort and reduced dosing frequency may aid patient compliance. ${ }^{46}$ Over a 7 -year time frame (from 2000 to 2006), approximately 7.8 million patients were treated with bromfenac ophthalmic solution in Japan; a total of 16 serious AEs were reported during that period, representing an incidence of $0.0002 \% .{ }^{47}$ Since the initial approval of bromfenac ophthalmic solution in Japan and the US, more than 26 million prescriptions of bromfenac have been reported. ${ }^{47}$

In the bromfenac $0.09 \%$ twice-daily study, ${ }^{29}$ the most common ocular AEs included iritis, abnormal sensations in the eye, eye pain, pruritus, posterior capsule opacification, 
ocular irritation, redness, or conjunctival hyperemia. For the majority of these AEs, the incidence was lower in the bromfenac group than in the placebo group. Only eye pruritus was reported in a higher proportion in the bromfenac group compared with the placebo group (3.9\% versus [vs] 2.9\%). ${ }^{29}$ No serious ocular AEs were reported in either group.

In the bromfenac $0.09 \%$ once-daily study, the overall incidence of AEs in the bromfenac $0.09 \%$ group (35.1\%, [196/559]) was significantly lower compared with those in the placebo group (55.0\%, [153/278]; $P<0.0001) .{ }^{30}$ Common AEs included eye inflammation, conjunctival hyperemia, eye pain, and foreign-body sensation. ${ }^{30}$ The incidence of these AEs also occurred more frequently in the placebo group compared with the bromfenac group; only conjunctival hyperemia occurred in a higher proportion of subjects in the bromfenac group compared with the placebo group ( $8.5 \%$ vs $3.7 \%$, respectively). The bromfenac group also had a lower incidence of macular edema (confirmed by clinician, optical coherence tomography, or fluorescein angiography) compared with the placebo group $(0.7 \%$ vs $1.4 \%){ }^{30}$

In the bromfenac $0.07 \%$ once-daily study, the incidence of adverse events was also significantly lower in the bromfenac $0.07 \%$ group compared with the placebo group $(28.8 \%$ vs $42.6 \% ; P=0.0041) .{ }^{44}$ The most commonly reported AEs were eye pain, anterior chamber inflammation, and foreign-body sensation, all of which occurred more frequently in the placebo group than in the bromfenac group. ${ }^{44}$

To date, there are no studies on the use of bromfenac $0.07 \%$ in the treatment of CME or as prophylaxis against CME. However, published studies evaluating the use of bromfenac $0.09 \%$ (in both once- and twice-daily formulas) and bromfenac $0.1 \%$ have generally found the use of bromfenac to result in less central retinal thickening and less change in macular volume compared with nepafenac; ${ }^{22,48}$ to be efficacious in preventing CME following cataract surgery - particularly in patients with nonproliferative diabetic retinopathy; ${ }^{23}$ and to be more successful at preventing CME than fluorometholone $0.1 \%$, dexamethasone $0.1 \%$, or betamethasone (all steroids). ${ }^{23,26}$

\section{Patient preference}

As part of the safety analysis of bromfenac $0.07 \%$, patient symptoms were assessed using the Ocular Comfort Grading Assessment (OCGA), a nonvalidated set of seven symptoms rated on a 0 to 3 severity scale. Subjects assessed and rated each of seven symptoms (eye pain, tearing, itching, foreign-body sensation, photophobia [light sensitivity], eye discharge, and haziness) as $0=$ none, $1=$ mild, $2=$ moderate, and $3=$ severe. A portion of the OCGA results were originally published in Walters et $\mathrm{al},{ }^{44}$ which integrated the results from two individual studies for safety and efficacy analyses. The individual studies are: bromfenac $0.07 \%$ - west US region; and bromfenac $0.07 \%$ - east US region. Results from the individual studies for all symptoms are summarized in the next sections.

The proportion of subjects who were pain free at day 1 was significantly higher in the bromfenac $0.07 \%$ group than in the placebo group in both regions. Additionally, change from baseline mean ocular pain in the bromfenac $0.07 \%$ group was significantly lower than in the placebo group in four of four visits in the west region and three of four visits in the east region. Mean photophobia demonstrated similar results - significantly less photophobia compared with placebo in four of four visits in the west region and three of four visits in the east region. At all four study visits (days 1, 3, 8, and 15) for both the west and east region studies, the bromfenac $0.07 \%$ group demonstrated significantly lower tearing severity compared with placebo. Foreign-body sensation was significantly less in the bromfenac $0.07 \%$ group compared with placebo at three of four visits in each region. The bromfenac $0.07 \%$ group was also better than placebo at three of four visits in the east region when change from baseline itching was evaluated. The bromfenac $0.07 \%$ group had similar changes from baseline in both mean eye discharge scores and mean haziness scores compared with the placebo group at any visit in both regions. Patients preferred bromfenac $0.07 \%$ over placebo for a majority of symptoms at most time points, which supports the comfort of bromfenac $0.07 \%$.

\section{Bromfenac compliance and adherence}

Cataract surgery is typically performed in an older population already known for poor medication compliance in other ophthalmic disorders. ${ }^{49-52}$ Commonly prescribed post-surgical ophthalmic medications with varying dosing schedules can be particularly troublesome for these patients to manage, especially if accompanied by stinging and/or burning upon instillation. Topical medications that maintain or improve upon the efficacy while reducing the medication treatment burden of their predecessors are likely to have a beneficial effect on patient adherence/compliance. ${ }^{47}$

Patient compliance or lack thereof can affect the safety and efficacy of a medication during study trials as well as in real-world settings. Questions raised range from whether 
Table 2 Discontinuation rates due to lack of efficacy

\begin{tabular}{llll}
\hline Study & Bromfenac group & Placebo group & $P$-value \\
\hline $\begin{array}{l}\text { Donnenfeld et al }{ }^{29} \\
\text { Bromfenac } 0.09 \% \text { BID }\end{array}$ & $3.1 \%(11 / 356)$ & $21.6 \%(37 / 171)$ & $P<0.0001$ \\
$\begin{array}{l}\text { Henderson et a }{ }^{30} \\
\text { Bromfenac } 0.09 \% \text { QD }\end{array}$ & $2.9 \%(17 / 584)$ & $32.6 \%(94 / 288)$ & $P<0.000$ I \\
$\begin{array}{l}\text { Walters et a }\left.\right|^{44} \\
\text { Bromfenac } 0.07 \% \text { QD }\end{array}$ & $3.2 \%(7 / 222)$ & $23.9 \%(52 / 218)$ & $P<0.000$ I
\end{tabular}

Abbreviations: BID, twice daily; QD, once daily.

the drug is efficacious or has only a limited effect to whether the dose is inadequate to demonstrate efficacy to whether lower levels of adherence may be due to adverse experiences. Insufficient medication adherence has been estimated to cost between $\$ 100$ billion and $\$ 289$ billion in the US and $€ 125$ billion in the European Union. ${ }^{53}$

Patient adherence and compliance is a hotly debated topic. In some disease states adherence is critical to survival rates, yet some degree of nonadherence is likely in a relatively high percentage of patients. ${ }^{54}$ Hauber et al found that patients are willing to pay for additional improvement not only in dosing frequency, but also in efficacy and side effects. ${ }^{55}$ In instances where long-term medical therapy is necessary to achieve desired outcomes, treatment efficacy can be compromised by suboptimal adherence, compliance, and persistence with the treatment in general. This occurs both in ophthalmology and in other clinical therapeutic areas. ${ }^{56}$

In all of the bromfenac studies reported here, the most common reasons for discontinuation of the test agent were lack of efficacy and adverse events. In the bromfenac $0.09 \%$ twice-daily study, $81.5 \%$ of subjects completed all 28 doses of bromfenac compared with $54.4 \%$ in the placebo group. ${ }^{32} \mathrm{~A}$ significantly higher proportion of subjects in the placebo group discontinued the test agent due to an adverse event compared with the bromfenac group (14.6\% [25/171] vs $2.8 \%$ [10/356]; $P<0.0001)$. Also, in the placebo group, $21.6 \%$ (37/171) of the subjects discontinued the test agent due to lack of efficacy compared with only $3.1 \%$ $(11 / 356)$ in the bromfenac group $(P<0.0001)$ (Table 2$)$. Similar results were seen in the bromfenac $0.09 \%$ oncedaily study, ${ }^{33}$ where early discontinuations from treatment occurred less frequently in the bromfenac group compared with the placebo group. Of the subjects in the placebo group, $16.2 \%$ (45/278) discontinued the test agent due to the occurrence of an AE compared with only 5.2\% (29/559) in the bromfenac group $(P<0.0001)$. In the bromfenac $0.07 \%$ once-daily study, the mean proportion of patient compliance, calculated as the number of doses received multiplied by 100 and divided by 16, was significantly higher in the bromfenac $0.07 \%$ group compared with the placebo group (91.2\% vs $76.0 \%$, respectively; $P<0.0001) .{ }^{44}$ As with the bromfenac $0.09 \%$ study, the primary causes for discontinuation in the placebo group in the bromfenac $0.07 \%$ study were lack of efficacy and occurrence of an adverse event. A significantly higher number of subjects in the placebo group discontinued the study agent due to the occurrence of an adverse event than in the bromfenac group (13.3\% [29/218] vs 5.0\% [11/222]; $P=0.0026)$. Furthermore, more subjects in the placebo group (23.9\% [52/218]) discontinued use early due to lack of efficacy than in the bromfenac group (3.2\% [7/222]; $P<0.0001)$.

\section{Conclusion}

The use of topical NSAIDs in ophthalmology has become well accepted because of their anti-inflammatory effects as well as their potential in improving patient comfort following surgery. Clinical studies on bromfenac have consistently confirmed the compound's potency, both in terms of penetration into ocular tissue and COX inhibition. Large cohort studies also have added to the literature on bromfenac's safety profile.

The lower concentration of bromfenac $0.07 \%$ combined with its once-daily dosing may help further improve patient adherence and compliance. Clinically, patients have been able to benefit from the easier administration and clinicians appreciate bromfenac's continued efficacy as an antiinflammatory medication that assists in achieving the best outcomes possible.

In conclusion, bromfenac is a molecule with a long history of effectively treating pain and inflammation following cataract surgery and should be viewed as a valuable tool in the ophthalmic NSAID armamentarium.

\section{Acknowledgments}

The authors wish to acknowledge the following contributions: Michelle Dalton, BS, ELS, for her medical writing; and Mauricio Munoz, PharmD, and Linda Wang, PharmD, for data review, verification, and editorial assistance. 


\section{Disclosure}

Bausch + Lomb provided financial assistance and editorial support in the preparation of this manuscript. $\mathrm{RR}$ is a consultant for Bausch + Lomb. The authors report no other conflicts of interest in this work.

\section{References}

1. Groessl EJ, Liu L, Sklar M, Tally SR, Kaplan RM, Ganiats TG. Measuring the impact of cataract surgery on generic and vision-specific quality of life. Qual Life Res. 2013;22(6):1405-1414.

2. Buch H, Vinding T, La Cour M, Appleyard M, Jensen GB, Nielsen NV. Prevalence and causes of visual impairment and blindness among 9980 Scandinavian adults: the Copenhagen City Eye Study. Ophthalmology. 2004;111(1):53-61.

3. [no authors listed]. Vision 2020: the cataract challenge. Community Eye Health. 2000;13(34):17-19.

4. Congdon N, O'Colmain B, Klaver CC, et al. Causes and prevalence of visual impairment among adults in the United States. Arch Ophthalmol. 2004;122(4):477-485.

5. Monnet D, Tépenier L, Brézin AP. Objective assessment of inflammation after cataract surgery: comparison of 3 similar intraocular lens models. J Cataract Refract Surg. 2009;35(4):677-681.

6. Prolensa [package insert]. Tampa, FL: Bausch and Lomb Inc.; 2013.

7. www.ema.europa.eu [homepage on the Internet]. Nevanac (nepafenac). European Medicines Agency; 2014 [updated September 18, 2013]. Available from: http://www.ema.europa.eu/ema/index.jsp?curl=pages/ medicines/human/medicines/000818/human_med_000928. jspandmid=WC0b01ac058001d124. Accessed March 25, 2014.

8. Ilevro [package insert]. Fort Worth, TX: Alcon Laboratories Inc.; 2013.

9. Donnenfeld ED, Perry HD, Wittpenn JR, Solomon R, Nattis A, Chou T. Preoperative ketorolac tromethamine $0.4 \%$ in phacoemulsification outcomes: pharmacokinetic-response curve. J Cataract Refract Surg. 2006;32(9):1474-1482.

10. American Academy of Ophthalmology Cataract and Anterior Segment Panel. Preferred Practice Patterns: Cataract in the Adult Eye. San Francisco: American Academy of Ophthalmology; 2011.

11. Warner TD, Mitchell JA. Cyclooxygenases: new forms, new inhibitors, and lessons from the clinic. FASEB J. 2004;18(7):790-804.

12. Findl $O$. Redefining the treatment paradigm for post-operative inflammation control - the role of topical non-steroidal anti-inflammatory drugs. Euro Ophthalmol Rev. 2010;4(1):54-59.

13. Colin J. The role of NSAIDs in the management of postoperative ophthalmic inflammation. Drugs. 2007;67(9):1291-1308.

14. Csukas S, Paterson CA, Brown K, Bhattacherjee P. Time course of rabbit ocular inflammatory response and mediator release after intravitreal endotoxin. Invest Ophthalmol Vis Sci. 1990;31(2):382-387.

15. Koay $P$. The emerging roles of topical non-steroidal anti-inflammatory agents in ophthalmology. Br J Ophthalmol. 1996;80(5):480-485.

16. Walters T, Raizman M, Ernest P, Gayton J, Lehmann R. In vivo pharmacokinetics and in vitro pharmacodynamics of nepafenac, amfenac, ketorolac, and bromfenac. J Cataract Refract Surg. 2007;33(9): $1539-1545$.

17. Renfro L, Snow JS. Ocular effects of topical and systemic steroids. Dermatol Clin. 1992;10(3):505-512.

18. Becker B. The side effects of corticosteroids. Invest Ophthalmol. 1964;3(5):492-497.

19. McGhee CN. Pharmacokinetics of ophthalmic corticosteroids. $\mathrm{Br} \mathrm{J}$ Ophthalmol. 1992;76(11):681-684.

20. Bartlett JD, Horwitz B, Laibovitz R, Howes JF. Intraocular pressure response to loteprednol etabonate in known steroid responders. $J$ Ocul Pharmacol. 1993;9(2):157-165.

21. O'Brien TP. Emerging guidelines for use of NSAID therapy to optimize cataract surgery patient care. Curr Med Res Opin. 2005;21(7): $1131-1137$.
22. Cable M. Comparison of bromfenac $0.09 \%$ QD to nepafenac $0.1 \%$ TID after cataract surgery: pilot evaluation of visual acuity, macular volume, and retinal thickness at a single site. Clin Ophthalmol. 2012; 6:997-1004.

23. Endo N, Kato S, Haruyama K, Shoji M, Kitano S. Efficacy of bromfenac sodium ophthalmic solution in preventing cystoid macular oedema after cataract surgery in patients with diabetes. Acta Ophthalmol. 2010;88(8):896-900.

24. Warren KA, Bahrani H, Fox JE. NSAIDs in combination therapy for the treatment of chronic pseudophakic cystoid macular edema. Retina. 2010;30(2):260-266.

25. Singh R, Alpern L, Jaffe GJ, et al. Evaluation of nepafenac in prevention of macular edema following cataract surgery in patients with diabetic retinopathy. Clin Ophthalmol. 2012;6:1259-1269.

26. Wang QW, Yao K, Xu W, et al. Bromfenac sodium $0.1 \%$, fluorometholone $0.1 \%$ and dexamethasone $0.1 \%$ for control of ocular inflammation and prevention of cystoid macular edema after phacoemulsification. Ophthalmologica. 2013;229(4):187-194.

27. Ahuja M, Dhake AS, Sharma SK, Majumdar DK. Topical ocular delivery of NSAIDs. AAPS J. 2008;10(2):229-241.

28. Cho H, Wolf KJ, Wolf EJ. Management of ocular inflammation and pain following cataract surgery: focus on bromfenac ophthalmic solution. Clin Ophthalmol. 2009;3:199-210.

29. Donnenfeld ED, Holland EJ, Stewart RH, Gow JA, Grillone LR. Bromfenac ophthalmic solution $0.09 \%$ (Xibrom) for postoperative ocular pain and inflammation. Ophthalmology. 2007;114(9): $1653-1662$.

30. Henderson BA, Gayton JL, Chandler SP, Gow JA, Klier SM, McNamara TR. Safety and efficacy of bromfenac ophthalmic solution (Bromday) dosed once daily for postoperative ocular inflammation and pain. Ophthalmology. 2011;118(11):2120-2127.

31. Ridgway D. Analgesics for acute pain: meeting the United States Food and Drug Administration's requirements for proof of efficacy. Clin J Pain. 2004;20(3):123-132.

32. Silverstein SM, Cable MG, Sadri E, et al. Once daily dosing of bromfenac ophthalmic solution $0.09 \%$ for postoperative ocular inflammation and pain. Curr Med Res Opin. 2011;27(9):1693-1703.

33. Miyake K, Ogawa T, Tajika T, Gow JA, McNamara TR. Ocular pharmacokinetics of a single dose of bromfenac sodium ophthalmic solution $0.1 \%$ in human aqueous humor. J Ocul Pharmacol Ther. 2008; 24(6):573-578.

34. Mukai K, Matsushima H, Gotoh N, et al. Efficacy of ophthalmic nonsteroidal anti-inflammatory drugs in suppressing anterior capsule contraction and secondary posterior capsule opacification. $J$ Cataract Refract Surg. 2009;35(9):1614-1618.

35. Bromday [package insert]. Irvine, CA: ISTA Pharmaceuticals, Inc.; 2011.

36. Brown HB, Taylor P. Muscarinic receptor agonists and antagonists. In: Hardman JG, Limbird LE, Molinoff PB, Ruddon RW, editors. Goodman and Gilman's The Pharmacological Basis of Therapeutics, 9th ed. New York: McGraw-Hill; 1996.

37. Sancilio LF, Nolan JC, Wagner LE, Ward JW. The analgesic and anti-inflammatory activity and pharmacologic properties of bromfenac. Arzneimittelforschung. 1987;37(5):513-519.

38. Walsh DA, Moran HW, Shamblee DA, et al. Anti-inflammatory agents. 3. Synthesis and pharmacological evaluation of 2-amino3-benzoylphenylacetic acid and analogues. J Med Chem. 1984;27(11): 1379-1388.

39. Kida T, Ogawa T, McNamara TR, et al. Evaluation of the Human COX-2 Inhibition of Amfenac, Bromfenac, Diclofenac, and Ketorolac. San Diego: American Society of Cataract and Refractive Surgery; 2007.

40. Ruiz J, López M, Milà J, Lozoya E, Lozano JJ, Pouplana R. QSAR and conformational analysis of the anti-inflammatory agent amfenac and analogues. J Comput Aided Mol Des. 1993;7(2):183-198.

41. Baklayan GA, Patterson HM, Song CK, Gow JA, McNamara TR. 24-hour evaluation of the ocular distribution of (14)C-labeled bromfenac following topical instillation into the eyes of New Zealand White rabbits. J Ocul Pharmacol Ther. 2008;24(4):392-398. 
42. Bronuck [package insert]. Osaka, Japan: Senju Pharmaceutical Co.; 2009.

43. Xibrom [package insert]. Irvine, CA: ISTA Pharmaceuticals, Inc.; 2010.

44. Walters TR, Goldberg DF, Peace JH, Gow JA. Bromfenac ophthalmic solution $0.07 \%$ dosed once daily for cataract surgery: results of 2 randomized controlled trials. Ophthalmology. 2014;121(1): 25-33.

45. Gow JA, Boyce JD, Reiser HJ, Berry R, Dao JT, Chandler SP. Randomized, placebo-controlled, integrated phase III clinical trials of a once daily, low-concentration, modified bromfenac ophthalmic solution following cataract surgery: focus on zero to trace anterior chamber inflammation. Poster presented at: Annual Meeting of the Association for Research in Vision and Ophthalmology; May 5; 2013; Seattle, WA.

46. Jones J, Francis P. Ophthalmic utility of topical bromfenac, a twicedaily nonsteroidal anti-inflammatory agent. Expert Opin Pharmacother. 2009;10(14):2379-2385.

47. Donnenfeld ED, Donnenfeld A. Global experience with Xibrom (bromfenac ophthalmic solution) $0.09 \%$ : the first twice-daily ophthalmic nonsteroidal anti-inflammatory drug. Int Ophthalmol Clin. 2006; 46(4):21-40.

48. Duong HQ, Westfield KC, Singleton IC. Comparing the efficacy of bromfenac $0.09 \%$ and nepafenac $0.1 \%$ post cataract surgery: a prospective evaluation. J Clinic Experiment Ophthalmol. 2011;2(8):177.
49. Okeke CO, Quigley HA, Jampel HD, et al. Adherence with topical glaucoma medication monitored electronically the Travatan Dosing Aid study. Ophthalmology. 2009;116(2):191-199.

50. Richter A, Anton SE, Koch P, Dennett SL. The impact of reducing dose frequency on health outcomes. Clin Ther. 2003;25(8):2307-2335.

51. Tsai T, Robin AL, Smith JP 3rd. An evaluation of how glaucoma patients use topical medications: a pilot study. Trans Am Ophthalmol Soc. 2007; 105:29-33.

52. Robin AL, Novack GD, Covert DW, Crockett RS, Marcic TS. Adherence in glaucoma: objective measurements of once-daily and adjunctive medication use. Am J Ophthalmol. 2007;144(4):533-540.

53. Heaney L, Hicks W, Seeruthun R. Adherence in Asthma: Comparing Clinical Trials to the "Real World." Pharmaceutical Product Development, LLC; 2013. Available from: http://www.ppdi.com/latestage-asthma/Adherence-In-Asthma_PPD-White-Paper.pdf. Accessed May 14, 2014.

54. Ichimaru N, Kakuta Y, Abe T, et al. Treatment adherence in renal transplant recipients: a questionnaire survey on immunosuppressants. Transplant Proc. 2008;40(5):1362-1365.

55. Hauber AB, Han S, Yang JC, et al. Effect of pill burden on dosing preferences, willingness to pay, and likely adherence among patients with type 2 diabetes. Patient Prefer Adherence. 2013;7:937-949.

56. Bock O, Felsenberg D. Biphosphonates in the management of postmenopausal osteoporosis - optimizing efficacy in clinical practice. Clin Interventions Aging. 2008;3(2):279-297.
Patient Preference and Adherence

\section{Publish your work in this journal}

Patient Preference and Adherence is an international, peer-reviewed, open access journal that focusing on the growing importance of patient preference and adherence throughout the therapeutic continuum. Patient satisfaction, acceptability, quality of life, compliance, persistence and their role in developing new therapeutic modalities and compounds to optimize

\section{Dovepress}

clinical outcomes for existing disease states are major areas of interest for the journal. This journal has been accepted for indexing on PubMed Central. The manuscript management system is completely online and includes a very quick and fair peer-review system, which is all easy to use. Visit http://www. dovepress.com/testimonials.php to read real quotes from published authors. 